\title{
Leiomyosarcoma of the inferior vena cava (IVC)
}

\author{
Amanjeet Singh $\cdot$ Azhar Perwaiz $\cdot$ Rahul Kakodkar $\cdot$ Samiran Nundy $\cdot$ Arvinder Soin
}

Received: 1 August 2008 / Accepted: 6 November 2008

(C) Association of Surgeons of India 2009

Sixty-year-old women diabetic patient, hypertensive on treatment presented with loose motions and pain abdomen of 20 days duration. Computed tomography (CT) scan (Fig. 1) and endoscopic ultrasound (EUS) (Fig. 2) were conducted with a basic question, "What is the clinical diagnosis?" and the answer we got was "Leiomyosarcoma of IVC".

CT scan shows $5.6 \times 5.6 \times 5 \mathrm{~cm}$ mass in retroperitoneum displacing the IVC. EUS showed tumour at right renal vein and IVC junction. EUS guided fine needle aspiration cytopathology (FNAC) suggestive of spindle cell tumour. Exploratory laparotomy revealed an $8 \times 6 \mathrm{~cm}$ well encapsulated tumour in retroperitoneum on right side fixed to IVC. Tumour with a wedge of IVC was excised and IVC repair was performed. Histopathology confirmed leiomyosarcoma of IVC.

\section{Discussion}

Primary venous leiomyosarcomas are rare tumours with about 400 cases reported [1]. These tumors show a female sex predilection.

Based on division of IVC in relation to renal and hepatic veins, they are described as three segments. Segment 1 is suprahepatic, segment 2 between hepatic and renal veins and segment 3 below renal vein with segment 2 being the most common [2].

Most patients are asymptomatic at presentation. Patient may present with abdominal pain, lower extremity

A. Singh · A. Perwaiz · R. Kakodkar · S. Nundy · A. Soin Department of Surgical Gastroenterology and Liver Transplantation, Sir Ganga Ram Hospital, New Delhi - 110 060, India

A. Soin $(\bowtie)$

E-mail: absoin@yahoo.com

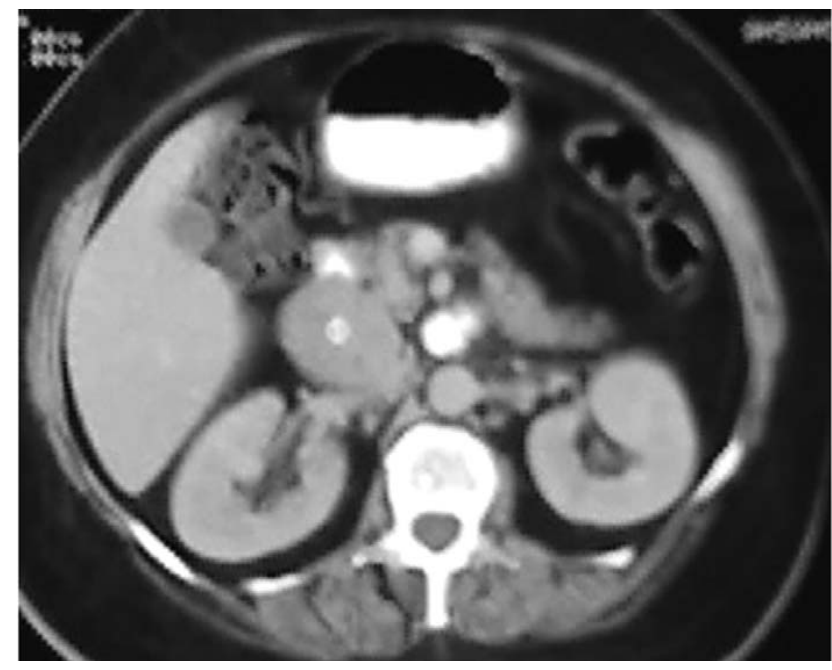

Fig. 1 Preoperative CT scan

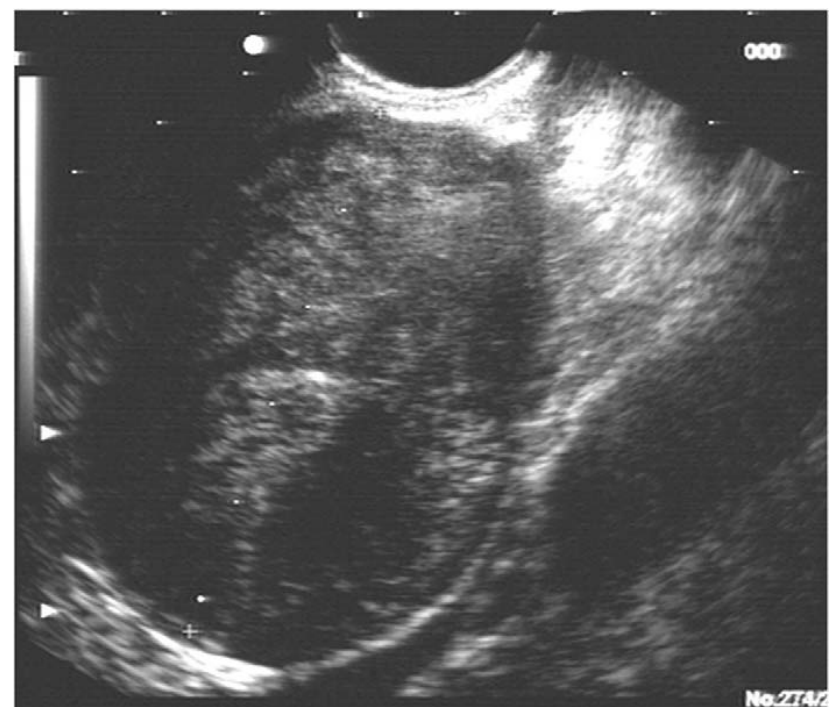

Fig. 2 Endoscopic ultrasound (EUS) 
edema due to IVC block, weight loss, or Budd-Chiari syndrome. Diagnosis is usually based on imaging including ultra-sound scan, CT scan or MRI. Invasion of adjacent organs is common and should be looked for in preoperative evaluation. Histologically, the tumor consists of spindleshaped interlacing bundles of cells with cigar-shaped nuclei and fibrillary eosinophilic cytoplasm [2].

Resection with negative margins is the treatment of choice [3]. If negative margins can be achieved, extended venous resection did not influence local recurrence rate or long-term outcome [4]. Poor prognostic factors include suprahepatic location, presence of Budd-Chiari syndrome, intraluminal tumor growth, and IVC occlusion [5]. Adjuvant therapy has not been shown to have much role till date [3].

Conflict of interest The authors do not have any disclosable interest

\section{References}

1. Hilliard NJ, Heslin MJ, Castro CY (2005) Leiomyosarcoma of the inferior vena cava Three case reports and review of the literature. An Diagn Pathol 9:259-266

2. Kulaylat MN, Karakousis CP, Doerr RJ, Karamanoukian HL, O'Brien J, Peer R (1997) Leiomyosarcoma of the inferior vena cava: a clinicopathologic review and report of three cases. J Surg Oncol 65:205-217

3. Hollenbeck ST, Grobmyer SR, Kent KC, Brennan MF (2003) Surgical treatment and outcomes of patients with primary inferior vena cava leiomyosarcoma. J Am Coll Surg 197:575-579

4. Mingoli A, Sapienza P, Cavallaro A, Di Marzo L, Burchi C, Giannarelli D, et al. (1997) The effect of extent of caval resection in the treatment of inferior vena cava leiomyosarcoma. Anticancer Res 17:3877-3881

5. Mingoli A, Cavallaro A, Sapienza P, Di Marzo L, Feldhaus RJ, Cavallari N (1996) International registry of inferior vena cava leiomyosarcoma: analysis of a world series on 218 patients. Anticancer Res 16:3201-5 